\title{
Relationship between emotional intelligence, personality, and self-perceived individual work performance: $A$ cross-sectional study on the Swedish version of TEIQue-SF
}

\author{
Annica K. V. Hjalmarsson ${ }^{1}$ (D) - Anna M. Dåderman ${ }^{1}$ (D) \\ Published online: 5 May 2020 \\ (C) The Author(s) 2020
}

\begin{abstract}
People with high emotional intelligence (EI) understand themselves and others well, and perform well at work. Trait EI has been described as "a constellation of emotion-related self-perceptions and dispositions" (Petrides and Furnham 2006), and can be measured by the Trait Emotional Intelligence Questionnaire Short Form (TEIQue-SF). The aims were to validate the Swedish version of TEIQue-SF by (1) investigating its internal consistency; (2) exploring its relationships with "Big Six" and "Dark Triad" personality traits as well as with self-perceived individual work performance; and (3) identifying which personality traits best explain variations in Trait EI, and whether this trait can predict variations in work performance over and above personality traits. Multi-occupational employees in Sweden $(N=228 ; M=34$ years, $S D=12.6$, range 16-71 years, 66\% women) with an average work experience of 14 years $(S D=11.5)$ were surveyed. In line with past research, internal consistency of TEIQue-SF was good, for the global Trait EI scale score (.86), and for one of its subdimensions (Well-Being) (.81). Global trait EI scale score and its subscales correlated negatively with Neuroticism and Machiavellianism, and positively with Extraversion, Agreeableness, Conscientiousness, Openness to Experience, and Narcissism. Sociability and Self-Control had, however, almost zero correlations with Machiavellianism. All subscales of global trait EI scale score correlated positively with Task Performance and Contextual Performance. On separate regression analyses, Big Six traits explained 48\%, and Narcissism 14\%, of the variation in global trait EI scale score. Trait EI accounted for a significantly larger proportion of the variation in Contextual Performance than any of the Big Six traits, and an additional $6 \%$ of the variation in Task Performance when controlling for gender, age, Neuroticism and Conscientiousness. The Swedish version of TEIQue-SF has good reliability as a global trait EI scale, reasonably theoretically and empirically grounded relationships with relevant variables for the workplace, and incremental validity over and above Big Six traits in predicting work performance in younger people with relatively high educational levels. Its reliability on the subscale level and its item functioning need to be further investigated in more heterogeneous samples.
\end{abstract}

Keywords Emotional intelligence $\cdot$ TraitEI $\cdot$ Swedish version of the TEIQue-SF $\cdot$ Big Six $\cdot$ Dark Triad $\cdot$ Self-perceived individual work performance

\section{Introduction}

What creates understanding for other people? What makes us understand ourselves? What can be the underlying feature that helps us increase our understanding of ourselves and other

Anna M. Dåderman

anna.daderman@hv.se; annadaderman@gmail.com

Annica K. V. Hjalmarsson

annica.hjalmarsson@hotmail.com

1 Department of Social and Behavioural Studies, Division of Psychology, Education, and Sociology, University West, SE-461 86 Trollhättan, Sweden people in social contexts? Past research has found that emotional intelligence (EI) plays an important role in the ability to understand oneself and other people (Schutte et al. 2001). EI is also essential for creating good collaboration with other people. By having good self-knowledge and good ability to read and understand the emotions and social essence of other people, it can become easier to understand them. EI also relates to how satisfied people are with romantic relationships (Malouff et al. 2014). Therefore, the concept of EI has been applied in several domains, such as clinical, educational, and organizational psychology (Petrides et al. 2016; Siegling et al. 2015).

High EI is an important interpersonal resource, which employees bring to organizations by developing good social relations at the workplace. For example, people with higher EI 
are more successful at problem solving, are generally more satisfied with life, and experience less anxiety (Bastian et al. 2005). High EI contributes to the ability of people to work effectively in teams with other people and manage workrelated stress better (Lopes et al. 2006). EI also plays an important role in the workplace for constructing altruistic behavior, contributing to increasing work performance, and creating a more positive attitude in the workplace (Carmeli 2003). It also mitigates the effect of the conflict that can arise between private life and work life when it comes to career and occupational engagement. EI is crucial for work life outcomes, such as commitment, health, job satisfaction, and job effectiveness (Miao et al. 2016, 2017). In other words, EI is a valid, useful, and impactful construct, and the EI trait enhances cooperative ability in both private and working life. In the current study, we will focus on the role of EI in working life.

\section{Definition of Trait Emotional Intelligence and its Assessment}

This study is about trait EI, which is distinct from ability EI (O'Connor et al. 2019) on a strong conceptual basis, according to Petrides and Furnham (2000, 2001), and reflects affective aspects of personality, being a "trait of emotional selfefficacy" (Petrides 2011, p. 660). Trait EI is defined as "a constellation of emotion-related self-perceptions and dispositions (e.g., emotion perception, emotion management, empathy, impulsivity) assessed through self-report questionnaires" (Petrides and Furnham 2006, p. 554).

In his doctoral dissertation, Petrides (2001) identified 15 different aspects framing the dimensional domain of the trait EI, grouped into four second-order subdimensions. According to Petrides (2009), there are four different subdimensions of trait EI: Emotionality, Self-Control, Well-Being, and Sociability. High levels of Emotionality imply an ability to perceive, express, and connect with emotions in self and others. This ability may be helpful in creating successful interpersonal relationships. SelfControl is useful in regulation and having control over emotions, impulses, and stress. Well-Being relates feelings across time based around achievements, self-regard, and expectations. Sociability is defined as being socially assertive and aware, managing others' emotions, and effectiveness in communication and participation in social situations. These dimensions comprise different aspects of trait EI, named "facets". For example, Well-Being comprises facets of self-esteem, trait happiness, and trait optimism, while Sociability comprises facets of assertiveness, emotion management, and social awareness (Petrides 2009). It is clear that trait EI is a complex construct comprising several subdimensions, each of them reflecting several facets. However, it has also been criticized for overlapping with higher-order personality dimensions, such as "Big Five" (e.g., Zeidner et al. 2004). Trait EI is placed at the lower levels of personality hierarchies and integrated within existing personality taxonomies rather than being independent of them (Vernon et al. 2008a). This means that trait EI co-varies with most of personality traits assessed through self-reports, but that it additionally, and independent, reflects "something" more - individual emotional experiences.

To measure trait EI and its dimensions, Petrides (2009) developed a questionnaire, Trait Emotional Intelligence Questionnaire (TEIQue). The questionnaire exists in both a long (TEIQue-LF) and a short (TEIQue-SF) form, translated into several languages. Both the long and the short form provide scale scores on the global trait EI as well as subscale scores on the four different subdimensions of EI. These subscales contribute direct to the global Trait scale score. TEIQue-LF comprises 13 facets, which reflect 13 out of the 15 different aspects framing the dimensional domain of the trait EI, identified by Petrides (2001); two of these facets, adaptability and sociability, contribute directly to the global trait EI scale score. The description of these 15 facets may be found in Chirumbalo et al. (2019, Table 1). This study focuses on the TEIQue-SF (Petrides and Furnham (2006).

The current study builds upon extant research on the Swedish version of Trait Emotional Intelligence Questionnaire Short Form (TEIQue-SF) (Petrides 2009; Petrides and Furnham 2006) in several ways. First, we examine the reliability and validity of the EIQue-SF on the subscale level. The majority of the studies on this measure tend to present results on reliability and validity on the global trait EI scale level. Only few studies (e.g., Feher et al. 2019; Siegling et al. 2015) reported results on reliability and validity on both levels. Second, to date, there is still no published study on this measure in Swedish-speaking people. Third, we examine EI, work functioning, and personality traits simultaneously in people holding jobs (i.e., not students, not only academics). Fourth, we examine the "Big Six" personality traits (Sibley 2012; Sibley et al. 2011), which in addition to the "Big Five" personality traits comprise the Honesty-Humility scale; this scale has, to date, not been examined in relation to EI. Fifth, to avoid the suppressor effect (Paulhus et al. 2004), we conduct separate regression analyses on the "Big Six" and "Dark Triad" personality traits (see below a brief description of these scales); past research (Furnham et al. 2013) has not always carried out separate regression analyses when two well-known measures comprise high-correlated constructs, such as for example extroversion and narcissism. Sixth, we examine correlations of the global trait EI scale score with scale scores measuring free dimensions of self-perceived individual work performance (Koopmans et al. 2012), which is a more effective measure in studies focusing on work performance. We are the first researchers to report correlations of this form of work performance with the global trait EI scale as well as with subscale scores. Finally, the summary (Table 3 ) of the systematic review and meta-analysis on the incremental validity of the TEIQue-SF (Andrei et al. 2016) shows that no previous study examined its incremental validity over and above 
Table 1 Correlations and descriptive statistics of the variables

\begin{tabular}{|c|c|c|c|c|c|c|c|c|c|c|c|c|c|c|c|c|c|c|c|c|}
\hline & $M$ & $S D$ & $S$ & $K$ & 1. & 2. & 3. & 4. & 5. & 6. & 7. & 8. & 9. & 10. & 11. & 12. & 13. & 14. & 15. & 16. \\
\hline 1. Trait EI & 4.95 & 0.74 & -0.56 & 0.60 & - & & & & & & & & & & & & & & & \\
\hline 2. EM & 5.22 & 0.89 & -0.72 & 1.16 & $.70^{*}$ & - & & & & & & & & & & & & & & \\
\hline 3. SC & 4.78 & 1.01 & -0.45 & 0.53 & $.65^{*}$ & .23 & - & & & & & & & & & & & & & \\
\hline 4. WB & 5.20 & 1.23 & -0.65 & -0.16 & $.85^{*}$ & $.47 *$ & $.40^{*}$ & - & & & & & & & & & & & & \\
\hline 5. SO & 4.62 & 0.91 & -0.18 & -0.04 & $.73^{*}$ & $.40 *$ & $.26^{*}$ & $.52 *$ & - & & & & & & & & & & & \\
\hline 6. $\mathrm{N}$ & 3.82 & 1.08 & 0.24 & 0.07 & $-.48 *$ & -.17 & $-.59 *$ & $-.38 *$ & $-.23 *$ & - & & & & & & & & & & \\
\hline 7. E & 4.14 & 1.34 & 0.01 & -0.44 & $.43^{*}$ & $.38 *$ & .03 & $.40 *$ & $.45^{*}$ & -.14 & - & & & & & & & & & \\
\hline 8. $\mathrm{O}$ & 5.27 & 1.06 & -0.83 & 0.50 & $.29 *$ & $.34 *$ & .10 & .13 & $.25^{*}$ & -.22 & $.30 *$ & - & & & & & & & & \\
\hline 9. A & 5.39 & 1.12 & -0.57 & -0.28 & $.40^{*}$ & $.64 *$ & .00 & $.30 *$ & $.28^{*}$ & .04 & $-.32 *$ & $.32 *$ & - & & & & & & & \\
\hline 10. $\mathrm{C}$ & 4.79 & 1.18 & -0.09 & -0.83 & $.26^{*}$ & .17 & $.23^{*}$ & .21 & .15 & -.17 & .02 & .00 & .13 & - & & & & & & \\
\hline 11. H-H & 5.00 & 1.25 & -0.56 & 0.14 & .07 & -.13 & .21 & -.11 & .02 & -.14 & -.10 & .02 & .03 & .12 & - & & & & & \\
\hline 12. MA & 2.60 & 0.71 & -0.27 & 0.14 & -.13 & $-.24 *$ & .00 & -.12 & -.02 & .02 & -.03 & -.03 & $-.24 *$ & -.08 & $-.38 *$ & - & & & & \\
\hline 13. NA & 2.70 & 0.60 & -0.18 & -0.52 & $.37 *$ & .20 & .12 & $.39 *$ & $.37 *$ & -.14 & $.46^{*}$ & .20 & .06 & .07 & $-.31 *$ & $.30 *$ & - & & & \\
\hline 14. PS & 1.87 & 0.56 & -0.96 & 0.78 & -.13 & -.14 & -.11 & -.11 & .00 & .03 & .14 & .07 & -.18 & -.17 & $-.38 *$ & $.48^{*}$ & $.33 *$ & - & & \\
\hline 15. TP & 2.48 & 0.89 & -0.23 & -0.33 & $.45^{*}$ & $.25^{*}$ & $.44^{*}$ & $.35^{*}$ & $.28^{*}$ & $-.35^{*}$ & .18 & .13 & .14 & $.31 *$ & .14 & -.04 & .11 & -.16 & - & \\
\hline 16. CP & 2.53 & 0.83 & -0.63 & -0.13 & $.43^{*}$ & .18 & $.28^{*}$ & $.39 *$ & $.40^{*}$ & -.22 & .21 & .16 & .16 & .16 & .04 & .02 & .19 & -.05 & $.52 *$ & - \\
\hline 17. CWB & 1.19 & 0.74 & 0.84 & 0.54 & -.15 & -.15 & $.25^{*}$ & .00 & -.06 & $.28 *$ & -.01 & -.12 & -.08 & -.05 & $-.30 *$ & .14 & .11 & .17 & .00 & .16 \\
\hline
\end{tabular}

$N=228 . * p<.05$, after the Bonferroni correction $(.05 / 136=.00037)$. The variable in focus is Trait Emotional Intelligence (EI), and its dimensions, measured by the Swedish version of the TEIQue-SF, and therefore its correlations with other study variables are in bold. $S=$ skewness. $K=$ kurtosis. Trait $\mathrm{EI}=$ global trait EI scale score consisting of all the 30 items of TEIQue-SF, EM = Emotionality, $\mathrm{SC}=$ Self-Control, WB = Well-Being, SO = Sociability, $\mathrm{N}=$ Neuroticism, $\mathrm{E}=$ Extraversion, $\mathrm{O}=$ Openness to Experience, $\mathrm{A}=$ Agreeableness, $\mathrm{C}=\mathrm{Conscientiousness}, \mathrm{H}-\mathrm{H}=\mathrm{Honesty}-\mathrm{Humility}, \mathrm{MA}=$ Machiavellianism, NA = Narcissism, PS = Psychopathy, TP $=$ Task Performance, $\mathrm{CP}=$ Contextual Performance, $\mathrm{CWB}=$ Counterproductive Work Behavior

personality traits on self-perceived individual work performance. In addition, only five of the 11 studies reported by Andrei et al. used samples of at least of 200 respondents. Therefore, the current study aims to fill a gap in the literature in several important ways.

\section{Personality Traits - the Big Five and the Sixth Trait}

Most studies investigating the validity of the TEIQue-SF (Andrei et al. 2016; O'Connor et al. 2017; Siegling et al. 2015; Stamatopoulou et al. 2016; Szczygiel et al. 2015) use the Five-Factor Model (FFM), also known as "Big Five" (McCrae and Costa 1997). It assumes that a person's personality is measurable through five different traits, namely Neuroticism, Extraversion, Openness to Experience, Agreeableness and Conscientiousness. To validate the Swedish version of the TEIQue-SF the current study uses the Big Six model, which is a new approach.

Ashton et al. (2000) and Ashton and Lee (2005) suggested that some characteristics were not captured by the FFM's traits and developed a sixth trait, namely Honesty-Humility, forming the "Big Six." The new personality trait HonestyHumility adds characteristic features and behaviors such as a person's levels of trust and morality, and sense of justice and honesty (Saucier 2009). Characteristics and behaviors that lower a person's Honesty-Humility score are their ability and willingness to resort to manipulation for personal benefit when interacting with other people and high levels of greed. Studies have shown that some subscales of the personality trait Honesty-Humility to some extent correlate with Agreeableness (Ashton and Lee 2001), but there is evidence to distinguish these characteristics due to the fact that Agreeableness consists of reactive cooperation towards other people, whereas Honesty-Humility includes active collaboration with other people (Hilbig et al. 2013).

\section{The Dark Side of Personality}

When studying workplace behavior some recent psychological studies apply deviant personality traits in their design (LeBreton et al. 2018), specifically the traits that are included in the "Dark Triad" (Paulhus and Williams 2002). The Dark Triad consists of three main traits, namely Machiavellianism, subclinical psychopathy, and subclinical narcissism. (In the rest of the text, we will simply refer to psychopathy and narcissism instead of using the terms subclinical psychopathy and subclinical narcissism.) The dark traits differ from each other with some overlap. The core of the Dark Triad personality traits also matches certain criteria found in the clinical definitions of personality disorders used in psychiatry, although not 
in the case of Machiavellianism according to the Diagnostic and Statistical Manual of Mental Disorders (American Psychiatric Association 2013). To date only one study (Fernandéz del Río et al. 2020) has validated the TEIQue-SF using the Dark Triad traits.

High levels of Machiavellianism imply manipulative behavior, a desire to maintain a good reputation, often being "cold," computational, and exploitative regardless of context, and the strategic ability to plan and use other long-term goals to achieve goals (Jones and Paulhus 2014; Paulhus and Williams 2002). Narcissism is characterized by the person having a strong desire for dominance and superiority, having a perception of being entitled to everything, and having a grandiose and grand perception of oneself in comparison to others (Paulhus and Williams 2002).

Psychopathy is a well-researched personality disorder (Patrick 2018), characterized by sensation seeking, and, generally, by highly impulsive behavior (Paulhus and Williams 2002). People with high levels of psychopathy tend to have low levels of anxiety and empathy, and their lack of affect and emotion leads to impulsive and insensitive behavior towards others (Jones and Paulhus 2014). Studies have shown that people with higher values on the Dark Triad scale have a greater tendency for counterproductive work behavior (CWB) (Jonason et al. 2012a, b), cheat more with their tasks at work, and devote more effort and time to plagiarism in education. Studies have shown that psychopathy correlates highest with CWB, although all the personality traits within the Dark Triad interact (DeShong et al. 2015).

\section{Relationship between Trait Emotional Intelligence and Personality Traits}

Significant relationships have been empirically demonstrated between trait EI and the various personality traits. Vernon et al. (2008a) found a negative relationship between Neuroticism and trait EI, which has been verified in other studies (Neustadt et al. 2011; Petrides et al. 2010). Veselka et al. (2009) demonstrated the same relationship in twin studies, but also found a positive relationship between Extraversion and EI, confirmed in a recent study by Szczygiel and Mikolajczak (2018). In the case of EI and the Dark Triad, studies show that some of these deviant personality traits relate to EI (Nagler et al. 2014). For instance, the connection between narcissism and emotional expression, as well as with emotional manipulation, is established. Psychopathy also clearly connects with emotional manipulation. Both narcissism and psychopathy also have positive links with emotional control.

The relationship between the Dark Triad and the Big Five has also been studied. A majority of the studies involving the Big Five show a negative correlation between all Dark Triad personality traits and Agreeableness (Furnham et al. 2013;
Hodson et al. 2009; Paulhus and Williams 2002; Vernon et al. 2008a). Other studies show the relationship between high values of Machiavellianism and psychopathy associated with negative values in Conscientiousness (Furnham et al. 2013; Jonason et al. 2012a, b). High values of Extraversion tend to be associated with high levels of narcissism (Vernon et al. 2008b). Due to possible suppressor effects, these results support conducting separate regression analyses when Big Five/Big Six and Dark Triad are investigated simultaneously as predictor variables.

\section{Emotional Intelligence, Personality Traits and Performance at Work}

Several meta-analyses with generally favorable conclusions toward EI (e.g., Joseph et al. 2015; Joseph and Newman 2010; Van Rooy and Visewesvaran 2004) analyzed the findings that people with high EI perform well at work as well as in non-work settings, such as sports and education. Joseph and Newman (2010), and Van Rooy and Visewesvaran (2004) have summarized studies on the predictive power of EI on work performance. Trait EI may have an enhancing effect on the positive aspects of work performance by showing other co-workers altruistic behavior, developing healthy social relationships, and maintaining a more positive attitude in the workplace. However, it is also known that people high in some of the Big Five personality traits (e.g., Conscientiousness) also perform well at work.

Studies show that the broad personality traits that have the most positive impact on work performance are Conscientiousness and emotional stability, that is, the opposite of Neuroticism (Salgado 1997). These personality traits are the most important regardless of the person's industry, profession and position in the organization. They have generalized validity across countries, organizations, and occupations. A recent study of Ramos-Villagrasa et al. (2019) examined this issue using a brief self-report scale for measuring individual work performance, and their results confirmed past research regarding Conscientiousness and Neuroticism. The impact and importance of other personality traits differ according to the person's type of industry and level within the organization. The study of Ramos-Villagrasa et al. comprised employees from different organizations. In their study, Extraversion also showed reasonable correlation coefficients (about .30) with two positive dimensions of work performance, namely Task Performance and Contextual Performance (Koopmans et al. 2012). Measurements including Honesty-Humility show that high values in this personality trait have a positive impact on the workplace (Johnson et al. 2011; Lee et al. 2005).

Meta-analyses have demonstrated both negative and positive relationships between work performance and Dark Triad personality traits (O’Boyle et al. 2012). Fernandéz del Río et al. (2020) found that employees with higher values of 
narcissism experienced better Task Performance and Contextual Performance. Machiavellians reported only better Task Performance. In contrast, those with higher values of psychopathy reported poor Task Performance. The characteristics found in Machiavellianism, narcissism and psychopathy work successfully in industries where a manipulative and exploitative attitude towards other people increases the chance of personal success. However, having high values for these characteristics can also entail negative effects in working life. For instance, interpersonal manipulation, which people with high values of Machiavellianism tend to engage in, often eventually leads to dead ends, as the targets of this attitude expose and detect the deception and manipulation and distance themselves from the person with the Machiavellian behavior.

By being a "trait of emotional self-efficacy" (Petrides 2011 , p. 660) it is useful to examine its incremental validity over and above personality traits in working life in different countries. In their systematic review and metaanalysis on the incremental validity of the TEIQue-SF, Andrei et al. (2016, Table 3) summarized 11 studies, including 32 analyses, with a strong evidence regarding incremental validity of trait EI, measured by this instrument, over and above broad personality traits (Big Five and "Giant Three") and other predictor variables on different outcome variables of individual functioning. Examples of investigated predictor variables are mood, happiness, cognitive ability, coping strategies, and health. Examples of examined outcome variables are somatic complains, happiness, burnout, sensation-seeking, and academic performance. The findings provided support for the incremental validity of the TEIQue-SF predicting additional criterion variance in $13(80 \%)$ of the 16 analyses reported.

Work performance is an important criterion in Human Resource management. However, only one study (Fernandéz del Río et al. 2020) examined TEIQue-SF's incremental validity over and above personality traits on self-perceived individual work performance using the Big Six and Dark Triad personality traits as predictor variables. In addition, only $26 \%$ of the analyses in Andrei et al. (2016) refer to data collected from a general population. A study of Siegling et al. (2015), which was not included in Andrei et al.'s analyses, is not an exception; the authors sampled their data among undergraduate students. We would add to past research by confirming these results in working people using a measure of selfperceived individual work performance (Koopmans et al. 2012) which had not to date been investigated in relation to EI.

\section{Aim of the Study and Research Questions}

The aim of this study was to validate the Swedish version of the TEIQue-SF by (1) investigating its internal consistency; (2) exploring its relationships with Big Six and Dark Triad personality traits as well as self-perceived individual work performance; and (3) identifying which personality traits best explain variations in trait EI and whether trait EI can predict variations in each dimension (Task Performance, Contextual Performance, and Counterproductive Work Behavior, CWB) of selfperceived individual work performance over and above personality traits.

The following four main questions guided this validation study of the Swedish version of Trait Emotional Intelligence Questionnaire Short Form (TEIQue-SF) (Petrides 2009; Petrides and Furnham 2006):

1. To what degree are the global trait EI scale score and its subscales internally consistent?

Hypothesis 1a: Based on past research on many translations and validation studies on the TEIQue-SF, the global trait EI scale score would show a good (> .80) (Heilbrun 1992) internal consistency as measured by Cronbach's alpha. We could not formulate any hypothesis regarding the internal consistency of this scale on the subscale level. Past research is sparse in this respect (O'Connor et al. 2019). Except for the Well-Being (e.g., Feher et al. 2019; Siegling et al. 2015) the subscales' internal consistencies tend to have relatively lower values than the full version.)

2. How does the global scale and each subscale of the Swedish version of TEIQue-SF relate to the different personality traits and dimensions in self-perceived individual work performance?

Hypothesis 2a: The global trait EI scale score and all its subscales would correlate negatively with Neuroticism and Machiavellianism (with the exception of Self-Control and Machiavellianism), and positively with Extraversion, Agreeableness, Conscientiousness, Openness to Experience, and Narcissism.

Hypothesis 2b: The global trait EI scale score and all its subscales would correlate positively with scores of Task Performance and Contextual Performance, and negatively with CWB.

3. Which personality traits explain best the variation in global trait EI scale score?

4. How much more than the "Big Six" trait scales does global trait EI scale score explain the variation in each dimension of self-perceived individual work performance? 


\section{Method}

\section{Participants}

Initially, we gathered data from 231 people. Due to excessive missing responses, we removed the data for three participants. The current group consists of 228 participants $(66.2 \%$ women). The average age of the participants was 34 years $(S D=12.6$; range $=16$ to 71 years $)$ with skewness of $0.87(S E=0.16)$, and kurtosis of -0.13 $(S E=0.32)$. About $52 \%$ of the participants worked fulltime or part-time (75\% employed); $29 \%$ were students working part-time. The average work experience was 14 years $(S D=11.5)$ with skewness of $0.83(S E=0.16)$ of and kurtosis of $-0.23(S E=0.32) ; 14$ participants had worked for less than 1 year. The two most prevalent levels of education were basic-level college or university education (current or completed, up to 3 years) (29.9\%) and intermediate-level college or university education (current or completed, from 3 years upwards) (26\%).

\section{Procedure}

Primarily, we invited potential respondents online via social media to participate in the study, but also through personal contacts and networks; $5-7 \%$ of the data is the result of direct personal contacts. We do not know how many people actively chose not to participate in the study or how many completed parts of it without completing the questionnaire, so it is not possible to calculate the response rate or loss. By answering and completing the questionnaire, the participant indicated that they agreed to participate in the study and approved that we could use the data gathered for research purposes in accordance with the guidelines of the Swedish Research Council (2002).

\section{Ethical Considerations}

According to Swedish law (2003:460, §2), ethical approval is not required when data are gathered anonymously. We have carried out this study in accordance with the recommendations of the Swedish Research Council (2002) by informing about the study through the initial formal notice prior to accessing the questionnaire. We guaranteed the participants that their answers were anonymous; particular, that they could not be identified by the Internet Protocol (IP) address of their computer, and that they could cancel their participation in the questionnaire at any time. All the participants gave their written informed consent in accordance with the Declaration of Helsinki.

\section{Measures}

We initiated the survey with five background questions pertaining to the participant: gender, age, educational level, number of working years, and main type of employment (e.g., full-time, part-time, self-employed, sick leave, parental leave, or student). In order to measure the various phenomena included in this study, we used Swedish versions of the instruments. The final survey was composed of four questionnaires, all of which measured different phenomena linked to personality or work performance. For each variable, a high score indicates a high level of the variable.

\section{The Trait Emotional Intelligence Questionnaire-Short Form (TEIQue-SF)}

The TEIQue-SF (Petrides 2009; Petrides and Furnham 2006) is a 30 -item self-report questionnaire. It is an abbreviated measure of the long version of the TEIQue (TEIQue-LF). The long version provides scores of four subdimensions and 15 different facets of trait EI scale, capturing characteristics such as self-esteem, adaptability, self-motivation, social awareness and emotional management (for a description of the 15 facets and their high scores, see Andrei et al. 2016, Table 1, p. 262; Petrides 2009).

The constructors of TEIQue-SF (Petrides 2009; Petrides and Furnham 2006) composed this measure by adding two items from each of the 15 facets of TEIQue-LF. They selected these items based on their best correlations with the respective total facet score. In doing so the scale constructors ensured broad coverage of the construct's sampling domain on the global trait EI scale level. All of the 30 items of the TEIQueSF comprise the global trait EI scale score. Only 26 of the TEIQue-SF's 30 items are assigned to compose scores of its subscales (for items comprising each subscale, see Laborde et al. 2016, Table 2). Consequently, an alternative scoring key for the TEIQue-SF allows for the computation of the subscale scores measuring four dimensions of trait EI on a 7-point Likert scale, ranging from 1 (Completely Disagree) to 7 (Completely Agree). The four subscales are Emotionality (8 items), Self-Control (6 items), Well-Being (6 items), and Sociability (6 items). With the TEIQue-SF it is not possible to assess scores of the trait EI scale facets. The Swedish version of TEIQue-SF is available free of charge for academic research purposes from http://psychometriclab.com/

In this study, the Cronbach's alpha reliabilities and mean inter-item correlations, respectively, were $.64 / .19$ for Emotionality, .61/.21 for Self-Control, .81/.43 for WellBeing, $.55 / .18$ for Sociability subscales, and $.86 / .16$ for the global trait EI scale. Cronbach's alpha is usually low when the number of items is below eight. Consequently, we did not exclude any items, due to the acceptable range (.15-.50; Clark 
Table 2 Results from two separate regression analyses with global trait EI as dependent variable

\begin{tabular}{|c|c|c|c|c|c|c|c|}
\hline Dependent variable & $R^{2}$ & Adj. $R^{2}$ & $F$ & Model & $B$ & $\beta$ & $p$ \\
\hline \multirow[t]{6}{*}{ Global trait EI } & \multirow[t]{5}{*}{.48} & \multirow[t]{5}{*}{.47} & \multirow[t]{5}{*}{41.59} & Neuroticism & -.29 & -.43 & $<.001$ \\
\hline & & & & Extraversion & .15 & .26 & $<.001$ \\
\hline & & & & Openness to Experience & .01 & .02 & .703 \\
\hline & & & & Agreeableness & .20 & .31 & $<.001$ \\
\hline & & & & Conscientiousness & .09 & .15 & .003 \\
\hline & .14 & .14 & 36.79 & Narcissism & .47 & .37 & $<.001$ \\
\hline
\end{tabular}

$R^{2}=$ this study, adj. $R^{2}=$ adjusted population value, $B=$ non-standardized coefficient, $\beta=$ standardized coefficient. All $F$ values reached $p<.001$. The models in the table comprise only those personality traits that correlated with TEIQue-SF global trait EI at $p<.05$, after the Bonferroni correction $(.05 / 136=.00037)$ (Table 1$)$ and Watson 1995) of reliabilities on the subscale level, reflected in the mean inter-item correlations.

It is worth to describe those items that in our study showed relatively poor $(.20-\sim .25)$ correlations with their own subscale. Firstly, Item 13 "Those close to me often complain that I don't treat them right" and Item 23 "I'm generally aware of my emotions as I experience them", both comprising Emotionality, showed that excluding them would not considerably improve the value of Cronbach's alpha for this subscale. Secondly, Item 22 "I tend to be involved in things I later wish I could get out of', comprising Self-Control, showed that excluding it would only slightly improve Cronbach's alpha from .61 to .62. Thirdly, the four "bad" items, based on their relatively low correlations with their own Sociability subscale were Item 6 "I can deal effectively with people", Item 10 "I often find it difficult to stand up for my rights", Item 11 "I'm usually able to influence the way other people feel", and Item 25 'I tend to 'back dawn' even if I know I'm right". Some of these items (Items 13, 22, 23, and 25) had low (.11-.17) itemtotal correlations with the global trait EI scale score, which may be reflected in a low value of mean inter-item correlation, despite an excellent Cronbach's alpha value.

\section{The Mini International Personality Item Pool-6 (Mini-IPIP6)}

Mini-IPIP6 (Donnellan et al. 2006; Sibley 2012; Sibley et al. 2011; Sibley and Pirie 2013) is a 24-item self-report questionnaire that measures the personality traits Neuroticism, Extraversion, Openness to Experience, Agreeableness, Conscientiousness and Honesty-Humility ("Big Six") on a 7-point Likert scale, ranging from 1 (Strongly Disagree) to 7 (Strongly Agree). The Swedish version of the Mini-IPIP6 is published in Dåderman and Ragnestål-Impola (2019, Appendix D).

When reviewing the mean inter-item correlation data, it was found that Item 5 ("I have a vivid imagination"), measuring Openness to Experience, differed in comparison with the values of the other items in the same trait (it showed a low correlation with the scale), and was therefore removed. After the removal, Cronbach's alpha reliabilities and mean interitem correlations, respectively, for the various scales in this study were .53/.22 for Neuroticism, .75/.43 for Extraversion, $.67 / .40$ for Openness to Experience, .68/.35 for Agreeableness, .65/.32 for Conscientiousness and .66/.33 for Honesty-Humility.

\section{The Short Dark Triad (SD3)}

SD3 (Jones and Paulhus 2014) is a 27-item self-report questionnaire that measures the Dark Triad personality traits narcissism, psychopathy, and Machiavellianism on a 5-point Likert scale, ranging from 1 (Strongly Disagree) to 5 (Strongly Agree). The Swedish version of the SD3 is published in Dåderman and Ragnestål-Impola (2019, Appendix C).

When reviewing the inter-item data, we found that Item 15 ("I feel embarrassed if someone compliments me") and Item 17 ("I'm an average person"), both measuring narcissism, as well as Item 20 ("I avoid dangerous situations") and Item 25 ("I have never gotten into trouble with the law"), both measuring psychopathy, differed in comparison with the values of the other items in the same trait. Therefore, we removed these items. After the removal, Cronbach's alpha reliabilities and mean inter-item correlations, respectively, for the various scales in this study were .78/.20 for Machiavellianism, .66/ .29 for narcissism and $.77 / .15$ for psychopathy.

\section{The Individual Work Performance Questionnaire (IWPQ)}

IWPQ (Koopmans et al. 2012) is an 18-item self-report questionnaire that measures self-perceived individual work performance on a 5-point Likert scale, ranging from 0 (Seldom) to 4 (Always); 0 (Never) to 4 (Often) for Counterproductive Work Behavior (CWB). The Swedish version of the IWPQ is published in Dåderman et al (2020, Appendix).

All items have a recall period of 3 months. IWPQ measures three dimensions, namely Task Performance, Contextual Performance, and CWB. The Task Performance scale (5 
items) measures how well one performs an actual task in a vigorous and technical way and is linked to the skills of work, and the quality and quantity of work. The Contextual Performance scale ( 8 items) measures factors linked to the organizational, social and psychological environment in which co-workers perform their duties, and includes behaviors that relate to collaboration, achievement, communication, and facilitation of equality and team performance. The CWB scale ( 5 items) defines a negative and disadvantaging behavior in the workplace, which expresses itself through behaviors such as deliberately performing tasks slowly and voluntary absence. When reviewing the mean inter-item correlation data, it was found that Item 4 ("I was able to carry out my work efficiently") measuring Task Performance differed in comparison with the values of the other items in the same dimension, and was therefore removed. After the removal, Cronbach's alpha reliabilities and mean inter-item correlations, respectively, for the various scales in this study were $.80 / .51$ for Task Performance, .89/.50 for Contextual Performance and .79/.44 for Counterproductive Work Behavior.

\section{Data Processing and Data Analyses}

The study participants' responses were coded into numbers in Microsoft Excel and then imported into the IBM Statistical Package for the Social Sciences (SPSS), version 25. Prior to analyses, the variables were examined for accuracy of data entry, missing values, and fit between their distributions and the assumptions of multivariate analyses. We manually entered single missing values, using averages per variable. The percentages of missing values for the various scales were: TEIQue-SF 0.19\%, Mini-IPIP6 0.20\%, SD3 0.19\%, IWPQ $0.15 \%$. We reversed items according to the manuals relating to each measurement scale instrument, and then grouped them together into the scales or subscales. Descriptive statistics such as mean $(M)$, standard deviation $(S D)$, skewness $(S)$ and kurtosis $(K)$ were also calculated. There were no univariate outliers (i.e., cases with extreme $z$ scores). Through Mahalanobis distances we could not identify any multivariate outliers with $p<.001$.

We examined internal consistency by Cronbach's alpha values and mean inter-item correlations. We defined "good" reliability, measured by Cronbach's alpha, when it was at least .80 (Heilbrun 1992). Clark and Watson (1995) recommended that the value of the mean inter-item correlation should be between .15 and .50 . Items that have a broader and higher target structure, such as Extraversion, may fall within the lower values (between .15 and .20) without such a low value in itself being problematic for the study. Narrower and Lower target structures, such as CWB, should be within the higher value range (between .40 and .50) in mean inter-item correlations.
We conducted correlation analyses between all used variables. Following other researchers (e.g., Feher et al. 2019), we computed correlations using scale scores for both global trait EI and for its four subdimensions. The Bonferroni correction was applied to the significance tests.

Before conducting regression analyses, we used routine pre-analysis screening procedures, such as examination of residuals scatterplots, to assess normality, linearity, and homoscedasticity. These assumptions were met. To determine the relative importance of personality traits for global trait EI, measured by the TEIQue-SF, we performed two separate standard regression analyses, one multiple and one bivariate. In the regression analyses, we used TEIQue-SF score as the dependent variable, and the personality traits, which correlated with this scale score at $p<.05$ after the Bonferroni correction, as independent variables. We used personality traits scale scores from the Big Six and Dark Triad measures in separate regression analyses to avoid the suppressor effect between the measurement scales.

To investigate whether global trait EI, measured by the TEIQue-SF, has an incremental validity over and above gender, age and personality traits, using self-perceived work performance as a baseline criterion, we carried out three hierarchical multiple regression analyses. In other words, we attempted to determine the relative importance of personality traits and global trait EI for the dimensions of individual work performance as outcome variables. In the regression analyses, Step 1 consisted of gender and age, Step 2 consisted of variables from the Big Six that correlated with the dimensions of IWPQ at $p<.05$ after the Bonferroni correction, and Step 3 consisted of the global scale score of TEIQue-SF. When investigating incremental effects of the TEIQue-SF, we used the global trait EI scale score as the dependent variable instead of its subscales. The reason was twofold; (1) The correlation coefficients between global trait EI scale score and the four subscale scores were significant and within a moderate-tostrong range in terms of magnitude; and (2) Past research (e.g., Siegling et al. 2015) showed similar incremental effects of TEIQue-SF subscales and global Trait scale. Siegling et al. noted that "replacing the TEIQue-SF subscales at Step 2, global composite showed consistent predictive effects in the same direction as the significant subscales" (p. 529). None of the Dark Triad traits "survived" the Bonferroni correction. Consequently, we did not analyze these traits.

\section{Results}

\section{Descriptive Statistics and Correlations between the Investigated Variables}

Table 1 presents descriptive statistics such as means $(M)$, standard deviations $(S D)$, skewness $(S)$ and kurtosis $(K)$ of all 
measuring instruments. All scales have a skewness less than \pm 1 , indicating that the distribution curve is relatively symmetrical for all variables. The only variable that has a kurtosis above 1 is the TEIQue-SF subscale Emotionality.

One of the main research questions for this study was to investigate which variables correlate with global trait EI scale score as well as with its subscales. Table 1 gives an indication of which variables correlate with each other, after the Bonferroni correction. One expected result was that global trait EI score, as well as all scores of the subscales of global trait EI, would correlate negatively with Neuroticism and Machiavellianism (with the exception of Self-Control and Machiavellianism), and positively with Extraversion, Agreeableness, Conscientiousness, Openness to Experience, and Narcissism, which was achieved with one exception (an almost zero correlation between Sociability and Machiavellianism). We found a positive correlation between global trait EI scale score and all scores of subscales of trait EI scale and Task Performance and Contextual Performance. All subscales of global trait EI scale were positively correlated with the global trait EI scale score. The magnitude of these correlations was within a moderate-to-high range (.65-.85).

\section{Which Personality Traits Explain the Variation in Global trait El Scale Score?}

Standard regression analysis with global trait EI as dependent variable and the Big Six personality traits as independent variables showed that the Big Six explained $48 \%$ of the variation in global trait EI. Moreover, we conducted a separate standard regression analysis with global trait EI as the dependent variable and the Narcissism trait from Dark Triad as the independent variable. It is evident that Narcissism trait accounted for $14 \%$ of the variability in trait EI. These results are presented in Table 2.

\section{How Much Does Global trait El Explain the Variation in Individual Work Performance?}

To investigate to what amount the personality traits of the Big Six and global trait EI could explain the variation in the three dimensions of self-perceived individual work performance, we carried out further analyses. We conducted these analyses to investigate whether the TEIQue-SF score has an incremental validity over and above gender, age, and personality traits. Table 3 shows the results from three separate hierarchical regression analyses where scores of the three dimensions of selfperceived Individual Work Performance Scale, Task Performance, Contextual Performance, and CWB, were all used as dependent variables.

Generally, gender was not a contributing factor to work performance when all variables were included in Step 3. We added age, because age seemed to play a slightly larger role than gender but it faded as other variables were added.

Personality traits seemed to help explain the variation in Task Performance; Neuroticism negatively, and Consciousness, positively. When we added global trait EI scale score it appeared as a significant and contributing factor. Global trait EI score increased the predictive ability of the regression model by 6 percentage points. The significant beta weights were all in the theoretically expected directions.

Contextual Performance had no personality variables correlated after the Bonferroni correction, and we investigated it only by gender, age, and global trait EI. We identified global trait EI as a contributing factor in explaining the variation in this dimension. The Global trait EI score increased the predictive ability of the regression model by 17 percentage points.

In line with theory and past research, global trait EI scale score did not contribute to explaining any variation at all in CWB, for which only personality traits (high Neuroticism and low Honesty-Humility) contributed to explaining the variation in negative behaviors at work, measured by the CWB.

In summary, the current study shows that both global trait EI and its four subdimensions correlate with personality traits and self-perceived individual work performance (Table 1) among people who have experience of working life. Our results indicate that the variables included in each model (Table 2) explain a substantial part of the variation in global trait EI. In other words, one can possibly predict the level of global trait EI based on a person's Big Six personality traits as well as Narcissism. We could also show that global trait EI predicts self-perceived individual work performance over and above the Big Six personality traits in Task Performance, and over and above gender and age in Contextual Performance (Table 3).

\section{Discussion}

\section{Internal Consistency of the Swedish Version of the TEIQue-SF}

Our study is the first to report the reliability coefficients of the Swedish version of the TEIQue-SF, on both the global scale level and subscale level. Cronbach's alpha of the global trait EI scale was good (Heilbrun 1992) and converged with the internal reliabilities reported by the scale constructors (e.g., Petrides 2009), as well as with other studies reporting reliability results on the scale translations (e.g., Feher et al. 2019, Jacobs et al. 2015; Laborde et al. 2016; Stamatopoulou et al. 2016; Szczygiel et al. 2015). This result supported Hypothesis 1 . We have, however, noted relatively poor mean interitemcorrelation on global trait EI, indicating an existence of items that did not correlate well with the global scale. This result may suggest this scale's multidimensionality, which is in line 
Table 3 Summary of linear hierarchical regression analyses of variables relating to dimensions of individual work performance

\begin{tabular}{|c|c|c|c|c|c|c|c|}
\hline & \multirow[t]{2}{*}{ Model } & \multicolumn{2}{|l|}{ Step 1} & \multicolumn{2}{|l|}{ Step 2} & \multicolumn{2}{|l|}{ Step 3} \\
\hline & & $\beta$ & $95 \% \mathrm{CI}$ & $\beta$ & $95 \% \mathrm{CI}$ & $\beta$ & $95 \% \mathrm{CI}$ \\
\hline \multirow[t]{8}{*}{$\mathrm{TP}$} & Gender & -.07 & {$[-.341, .094]$} & $-.15^{*}$ & {$[-.455,-.046]$} & -.09 & {$[-.355, .049]$} \\
\hline & Age & $.17^{*}$ & {$[.002, .019]$} & .08 & {$[-.003, .013]$} & .06 & {$[-.004, .011]$} \\
\hline & Neuroticism & & & $-.32 * *$ & {$[-.332,-.146]$} & $-.19 * *$ & {$[-.238,-.034]$} \\
\hline & Conscientiousness & & & $.25 * *$ & {$[.087, .247]$} & $.20 * *$ & {$[.055, .212]$} \\
\hline & Trait EI & & & & & $.29 * *$ & {$[.166, .456]$} \\
\hline & $F$ & & $3.79 *(2,225)$ & & $25.61 * *(2,223)$ & & $17.81 * *(1,223)$ \\
\hline & $R^{2} / \Delta R^{2}$ & & .03 & & .21 & & .27 \\
\hline & Adj. $R^{2} / \Delta R^{2}$ & & .02 & & .20 & & .26 \\
\hline \multirow[t]{6}{*}{$\mathrm{CP}$} & Gender & .05 & {$[-.152, .340]$} & .09 & {$[-.063, .385]$} & & \\
\hline & Age & $.15^{*}$ & {$[.001, .020]$} & .06 & {$[-.004, .013]$} & & \\
\hline & Trait EI & & & $.43^{* *}$ & {$[.367, .657]$} & & \\
\hline & $F$ & & $2.84(2,225)$ & & $48.27 * *(1,224)$ & & \\
\hline & $R^{2} / \Delta R^{2}$ & & .03 & & .20 & & \\
\hline & Adj. $R^{2} / \Delta R^{2}$ & & .02 & & .19 & & \\
\hline \multirow[t]{8}{*}{ CWB } & Gender & -.01 & {$[-.241, .210]$} & .02 & {$[-.186, .259]$} & .02 & {$[-.193, .267]$} \\
\hline & Age & $-.21 * *$ & {$[-.022,-.005]$} & -.10 & {$[-.015, .002]$} & -.10 & {$[-.015, .002]$} \\
\hline & Neuroticism & & & $.23 * *$ & {$[.075, .275]$} & $.18^{*}$ & {$[.061, .291]$} \\
\hline & Honesty-Humility & & & $-.24 * *$ & {$[-.243,-.074]$} & $-.23 * *$ & {$[-.243,-.073]$} \\
\hline & Trait EI & & & & & .00 & {$[-.157, .163]$} \\
\hline & $F$ & & $5.23 * *(2,225)$ & & $14.75 * *(2,223)$ & & $0.00 * *(1,222)$ \\
\hline & $R^{2} / \Delta R^{2}$ & & .04 & & .16 & & .16 \\
\hline & Adj. $R^{2} / \Delta R^{2}$ & & .04 & & .14 & & .14 \\
\hline
\end{tabular}

$N=228 . * p<.05, * * p<.01 . \mathrm{CI}=$ Confidence Interval. $\mathrm{TP}=$ Task Performance, $\mathrm{CP}=$ Contextual Performance, $\mathrm{CWB}=$ Counterproductive Work Behavior. The only predictors added at Step 2 are the personality traits from the "Big Six" that correlated with dimensions of the individual performance at $p<.05$, after the Bonferroni correction (see Table 1)

with the notion that the internal structure of the scale as a global trait EI measure is not yet well-established with a high degree of fidelity. For example, Perera (2015) was concerned about the latent structure of item response data derived from the TEIQue-SF, that is, its evidence for dimensional and construct validity. Perera observed cross-loadings of sex items (Items 8, 10, 15, 19, 22 and 23) comprising Self-Control. These items cross-loaded from Sociability and Emotionality. This finding may partly explain the relatively poorer reliability of these three subscales in our study, and also the poor mean inter-item correlation of the global trait EI scale. Consequently, investigators should present their results on the subscale level, and not only report psychometric properties of EI measured at the global trait EI scale score level, because, according to Perera, there is no support for unidimensional representation of this scale. The internal consistencies in this study, measured by Cronbach's alpha, were relatively poor $(<$ .70) on the subscale level of three (Sociability, Self-Control, and Emotionality) of the four EI dimensions. The reliability of Self-Control and Emotionality tends to be lower in published studies than for Well-Being, which is in line with our results. Not all studies report values of Cronbach's alpha at subscale level (e.g. Cooper and Petrides 2010; Szczygiel et al. 2015). The reported levels of Cronbach's alpha are about .60 for SelfControl and Emotionality in some studies (e.g. Petrides et al. 2016; Stamatopoulou et al. 2016), while Jacobs et al. (2015) also found a low value for Emotionality (.58) in their German version of TEIQue-SF. Some studies have reported somewhat higher Cronbach's alpha values, but still about only .70, for Sociability, Self-Control, and Emotionality (e.g., Feher et al. 2019; Laborde et al. 2016; Siegling et al. 2015). Heilbrun (1992) suggested that in applied settings, particularly in health care settings "the use of tests with a reliability coefficient of less than .80 is not advisable" (p. 265).

One explanation, based on results from the IRT study of Cooper and Petrides et al. (2010), is an existence of some items with somewhat poor psychometric properties, although the majority of the items showed moderate values of the discrimination parameter $a$. Item 20, "On the whole, I'm pleased with my life", and Item 24, "I believe I'm full of personal 
strengths", had high $a$ values. These items comprise WellBeing (compounding Facet Self-Esteem), which in our study also had a good internal consistency. Interestingly, Cooper and Petrides identified one "bad" item with a very low discriminating "power" $(a=0.61)$. This one was Item 25 , "I tend to 'back down' even if I know I'm right". This item is comprised in the Sociability subscale. In our study, this item had the lowest value (.20) of item-total correlation with its own subscale. This item also lowered the mean interitem correlation of the global trait EI scale score, which also Item 13, "Those close to me often complain that I don't treat them right", did. Cooper and Petrides used Item 13 (see their Fig. 1, p. 452 ) as an example of an item with poor psychometric properties.

Cooper and Petrides et al. (2010) showed in their IRT analysis that the threshold parameters $\left(b_{1}\right.$ to $\left.b_{4}\right)$ of the IRT were low, indicating that people "relatively low on the trait EI were still agreeing with them" (Cooper and Petrides 2010, p. 451). Thus, the item wordings are not too difficult to comprehend. We may still consider that the measurement per se (i.e., the interface between our set of questionnaires, the participants, and the testing environment) influenced the Cronbach's alpha values. As the participants' average age was low, it is possible that interpretation and/or linguistic perception of the test items can partly explain this aspect. In their recent meta-analysis of coefficient alpha, Greco et al. (2018) state that different sample-specific factors may influence Cronbach's alpha, which "is a property of test scores rather than of the test itself" (p. 586).

One intriguing question is, however, why the Cronbach's alpha value for the Sociability subscale of the TEIQue-SF was as low as .55 in our study. It was, however, a slightly larger than the Cronbach's alpha value of .47 of the Chinese sample (Feher et al. 2019). Feher et al. could not explain this low reliability of this subscale. The sociability subdimension of trait EI reflects, at least in theory (Petrides 2009), social assertiveness and awareness. It also reflects an ability to manage others' emotions, and effectiveness in communication and participation in social situations. We could not identify any particular item that was significantly worse than others were although some items correlated poorly with the global scale score (see the description of our relatively "bad" items in the Method section). However, the majority of items correlated at least .20 with their own subscale, which is commonly regarded as an acceptable value for exploratory purposes. Two of the six items correlated higher than .40 with their own subscale.

Another explanation, probably the most likely one, for the relatively low values of Cronbach's alpha may be that this is not an appropriate measure for the internal consistency of scales comprising fewer than eight items. A more appropriate measure is therefore mean inter-item correlation, which should be at least .15 (in our study it was .18). We believe that this explanation is valid for the remaining subscales of the TEIQue-SF.

\section{Correlations between Investigated Variables}

The study results (Table 1) supported Hypothesis 2a and Hypothesis $2 b$ with two exceptions. The exceptions were that Self-Control as well as Sociability had almost zero correlations with Machiavellianism. The fact that Neuroticism had negative correlations with all subscales of trait EI was an expected result in this study based on theory and previous research. Persons with higher levels of trait EI are more capable of managing negative emotions, and they may choose to act properly with a calm and positive outlook despite any negative emotions (Petrides 2009). Based on a previous twin study (Petrides et al. 2011), we expected that Machiavellianism would correlate negatively with Sociability, but this result was not achieved. According to the definition of Machiavellianism, people who are high in this trait are not expected to be sociable. One explanation may be that Sociability can be traced back to relatively poor reliability while assessed by TEIQue-SF. Another explanation is that this result may be sample specific and calls for further investigation in a more heterogeneous sample of professionally active participants. Two other variables that also achieved positive correlations with all subscales of the global trait EI scale were Task Performance and Contextual Performance. This was also an expected result, as previous research in this area showed that EI has a positive correlation with work performance (Carmeli 2003; Cote and Miners 2006). Another correlation that achieved an interesting but anticipated and negative correlation with CWB was Honesty-Humility. This is not surprising considering the characteristics of both CWB and HonestyHumility, which is in line with previous research (Ceschi et al. 2016). An expected relationship that occurred beyond the dimensions of EI was the relationship between Extraversion and Narcissism. The outward and attention-seeking characteristics that follow both of these personality traits explain the positive relationship and confirm previous research (Furnham et al. 2013).

\section{Which Personality Traits Best Explain the Variation in Global trait El?}

The standard multiple regression analysis provided data that can partly explain the variation in global trait EI. It emerged that Neuroticism had a strong negative relationship with global trait EI, which is in line with previous research (Petrides et al. 2010; Vernon et al. 2008a). In our study, Extraversion did show a similar positive relationship in comparison with previous research. Our results were also line with past research regards the positive relationship between Agreeableness and global trait EI. Overall, the Big Six personality traits explained 
almost half of the variation in global Trait EI. HonestyHumility did not show any significant correlation with global Trait EI, and was therefore not included in the regression model.

In our study, Narcissism showed a strong relationship with global Trait EI, which is also in line with previous research (Plouffe et al. 2017). A possible reason for the strength of the variation that is explained by Narcissism in this study could be that we did not mix the Big Six traits together with the trait from Dark Triad in the same regression analysis. In our study, Narcissism explained $14 \%$ of the variation in global Trait EI. Dark Triad traits had, in our study, nonsignificant correlations with all three dimensions of individual work performance, that is, Task Performance, Contextual Performance, and CWB (see Table 1), which contradicts other recent results (Fernandéz del Río et al, 2020).

\section{Incremental Validity of Trait El Over and above Personality Traits on Self-Perceived Individual Work Performance}

In the hierarchical regression analyses (Table 3), it was obvious that Trait EI (here: global Trait EI scale score, measured by the Swedish version of the TEIQue-SF) plays a role among the positive work performance aspects. Age did play a role in explaining the variation of all of the dimensions of Individual Work Performance to begin with. However, when personality traits were entered into our regression models with Task Performance and CWB as dependent variables, age did no longer contribute to the variation in these dependent variables. Gender only seemed to explain some of the variation in Task Performance when personality traits were entered. In line with recent research (Ramos-Villagrasa et al. 2019), Task Performance also seems to be a "product" of the personality traits Conscientiousness and Neuroticism. In the study of Ramos-Villagrasa et al., the scale score of the Spanish version of the IWPQ Task Performance correlated with Conscientiousness at .47, and with Neuroticism at -.25 . In our study, these correlations had the same direction, but somewhat different values (.31 respectively -.35 , see Table 1$)$. Consequently, these two traits explained some of the variation in this dependent variable (see the significant beta weights presented in Table 3), but not as much as Trait EI explained. Concerning Contextual Performance, no personality traits contributed to explaining the variation in this dependent variable. It is due to lack of significant correlations between personality traits and Contextual Performance (see Table 1). All of the correlation coefficients were weak in terms of magnitude, and varied between -.22 (Neuroticism) and .20 (Extroversion). Consequently, no personality traits were entered into our regression model. Therefore, Trait EI explained a great deal of the variation in Contextual Performance. This result indicates that global Trait EI is a valid, useful, and impactful construct that facilitates co-operation in working life, because Contextual Performance comprises all forms of extra tasks or initiatives that are outside the job description. Other labels for this aspect of work performance are, for example, extra-role performance and organizational citizenship behavior. An interesting result was that Trait EI could not explain any variation in CWB.

\section{Methodological Considerations}

Since the number of participants was above 200, there were enough participants to rule out a fluctuating result (Schönbrodt and Perugini 2013). The spread of the participants' age was wide and their average age was about 30 years. The wide age distribution increases the generalizability of the results. One can assume that the majority of the personality traits included in the study potentially had not achieved the stabilization and duration induced by age and work experience (Briley and Tucker-Drob 2014). Researchers have observed that a person's EI improves with age (Nelis et al. 2009; Petrides and Furnham 2006). Additional background factors that can confirm this assumption are that the second largest current form of employment among the participants consisted of working students and that the average working experience calculated in years was 14. Some participants indicated their work experience, expressed in years, as being none (0), which can be interpreted as either not currently working at all or total lifetime work experience not exceeding one year. The participants were generally highly educated, and many of them were current students improving their skills by, for instance, combining their current part-time employment with university studies. Together with their low average age and limited work experience, we can interpret their work experience as not yet having entered working life or having become stabilized in working life after graduation. Taking into account all background facts, especially the participants' generally low work experience expressed in years, we can possibly assume that the participants would not have as long vocational experience to provide the same results as would a study population comprising older participants with more work experience. Conducting studies with a different selection of respondents may produce different results. Since participants were anonymous in this study, there is no way to grant that the information given by the participants are all correct. This is an issue that is inevitable when performing this kind of data collection.

To ensure the reliability of the measuring instruments, we have scrutinized all variables for means of inter-item correlations. In total, we removed six items from other instruments than TEIQue-SF, because they differed significantly from the other items. Since the remaining items still met the minimum number of items per trait required to measure with certainty, the removals do not constitute a problem. However, we did not remove any items comprising the subscales of the Trait EI 
scale. It may be interesting for future studies to explore whether the same items show relatively poor correlations with their own subscale.

Because we tried to prevent the low reliability of variables from influencing our conclusions, we excluded a total of six items from other measures than TEIQue-SF. One of the removed items was Item 17, "I'm an average person", which relates to measuring Narcissism by SD3. When providing feedback after their participation in the study, a considerable number of younger participants stated that they did not understand what the word average ("ordinary") meant.

Another item, linking to lower work experience was Item 4, "In the last three months I have been able to perform my work well with as little time and effort as possible", which measures Task Performance by IWPQ. We removed this item because it had low correlation with its own subscale. Considering that 14 participants had answered that they had worked for less than a year, one might assume that confusion about how to deal with the instruction to recall a three-month period may be due to a lower correlation with the dimension of Task Performance. However, there may be another reason why this item had a lower correlation with the dimension, since we did not need to remove other items that measure the same variable, and thus did not ensure that work experience is a contributing factor. What may have contributed is the freedom of interpretation that the item gives rise to; one may interpret this item as making the least possible work effort to meet work requirement, but it also as making the best effort without "playing time" to carry out their work in a professional way. If the freedom of interpretation is the reason for its deviation, it could be due to the age, level of education and work experience of the participants. We are aware that these deletions of items could negatively influence the measurability capacity that these items would offer.

\section{Possible Theoretical and Practical Implications of the Study}

This study was the first to validate a scale recently translated into Swedish: the Trait Emotional Intelligence QuestionnaireShort Form. Furthermore, it is the only study conducted to investigate the relationship between TEIQue-SF and IWPQ. The study is one of few that have used TEIQue-SF among working people; most studies on TEIQue-SF used students and academics. The study is also one of a handful of studies that have investigated the relationship between Trait EI and the Dark Triad, as well as one of the few studies that have investigated the relationship between Trait EI and the Big Six. Finally, we have also reported reliability and validity results of the TEIQue-SF on the subscale level, which is unusual. In addition, we have enriched ongoing methodological discussions on the quality of some items of the TEIQue-SF. Thereby, the current study in several ways supplements extant research.

\section{Suggestions for Future Studies}

Despite satisfactory results, we doubt that a cross-sectional study could ever identify a clear cause-effect relationship. A longitudinal study in applied settings, such as a workplace, would be of interest. Another possibility for future research would be to carry out a similar study on one or more sample groups that differ significantly from each other (for example a more diverse working population and/or a population with a more heterogeneous education level) and to compare the results between the groups.

TEIQue-SF's reliability on the subscale level, as well as item functioning, need to be further investigated in samples that are more heterogeneous. We could only trace two studies (Cooper and Petrides 2010; Zampetakis 2011) investigating item functioning of this scale by applying IRT. These studies used the same database of English-speaking people, but different methods, and identified some items with poor or only moderate item functioning, meaning that these items do not contribute well to the scale. Our reliability analyses showed (see the Method section) that the same items contributed to a low inter-item correlation with the Trait EI scale score. Possibly, other items from the longer version of the TEIQue should be included in the short version, by adding items with a better cross-cultural functioning and by dropping "bad" items. As already mentioned, Cooper and Petrides identified only two items with a very high discriminating power, both capturing the Well-Being Trait EI subdimension, which also in our study had a good Cronbach's alpha value (.81). These powerful "good" items were Item 20, "On the whole, I'm pleased with my life", and Item 24, "Given my circumstances, I feel good about myself". Then, researchers lacking time to apply all the 30 items of the TEIQue-SF would substitute the 30 items with the two powerful items, but the question is whether using the best items to substitute other items is enough to measure a psychological construct. An additional question is what the two items actually measure; it is possible that they only measure the construct of well-being in highly narcissistic people.

\section{Conclusions}

The study achieved its aims and validated the Swedish version of TEIQue-SF providing results that substantially add to our current knowledge. To validate it we have used new measures, Mini-IPIP6, SDT3, and IWPQ, and conducted our study in a relatively large sample of people holding jobs. We conclude that, although its reliability on the subscale level and its item functioning need to be further investigated in more heterogeneous samples, the Swedish version of the TEIQue-SF has good reliability in terms of the global Trait EI scale score as well as of the Well-Being subscale. It also has reasonably 
theoretically and empirically grounded relationships with relevant variables for the workplace, and incremental validity over and above the Big Six traits in predicting individual work performance in younger people with relatively high educational levels.

We hope that the new findings highlighted in the study will stimulate further research. When using this scale some authors report only Cronbach's alpha for the global TEIQue-SF. We have identified several items with relatively poor correlations with their own subscales. Reporting also mean inter-item correlations may stimulate more cross-cultural research on the item level of the TEIQue-SF. As the four subscales of the TEIQue-SF seem to show different reliability coefficients in different populations, as reported by different authors (e.g., Feher et al. 2019; Siegling et al. 2015), we recommend investigators to calculate the internal consistency and the mean inter-item correlations for the global EI measure as well as its four dimensions.

Acknowledgments This manuscript is based on the Annica Hjalmarsson's Bachelor's thesis (Hjalmarsson, A. (2018). Samband mellan emotionell intelligens, personlighet och arbetsprestation - en tvärsnittsstudie som validerar den svenska versionen av TEIQue-SF [Relationship between emotional intelligence, personality and work performance - a cross-sectional study validating the Swedish version of TEIQue-SF]. Unpubl. Bachelor's thesis in Psychology, University West, Trollhättan, Sweden, under the second author's supervision. This work has not been published before in the English language. Parts of this research were presented by both authors at the 3rd World Conference on Personality, held from the 2nd to 6th April, 2019, in Hanoi, Vietnam. The participation in the conference in Vietnam was funded to the second author by a research grant from University West, Trollhättan, Sweden. We are grateful to the participants for answering our questions, to Åke Hellström for his checking this and previous versions of the manuscript and providing valuable comments, and to Patrick Reis for his editing and proofreading assistance of the former version of this paper.

Author Contributions Annica Hjalmarsson did the web survey (Google Forms), organized data collection, performed data entry, analyzed the data, conducted analyses, wrote the article, and revised the present version of the manuscript. Anna Dåderman wrote the article, and revised the previous and the present versions of it. Both authors designed the study, prepared the set of questionnaires, contributed to the conceptualization and design of the manuscript, proofread and accepted the manuscript before submission and publication.

Funding Information Open access funding provided by University West. University West also financially supported the second author during the preparation of this article.

\section{Compliance with Ethical Standards}

Conflict of Interest The submitted work was carried out without the presence of any personal, professional or financial relationships that could potentially be construed as presenting a conflict of interest.

Open Access This article is licensed under a Creative Commons Attribution 4.0 International License, which permits use, sharing, adaptation, distribution and reproduction in any medium or format, as long as you give appropriate credit to the original author(s) and the source, provide a link to the Creative Commons licence, and indicate if changes were made. The images or other third party material in this article are included in the article's Creative Commons licence, unless indicated otherwise in a credit line to the material. If material is not included in the article's Creative Commons licence and your intended use is not permitted by statutory regulation or exceeds the permitted use, you will need to obtain permission directly from the copyright holder. To view a copy of this licence, visit http://creativecommons.org/licenses/by/4.0/.

\section{References}

American Psychiatric Association. (2013). Diagnostic and statistical manual of mental disorders (5th ed.). Arlington: American Psychiatric Publishing.

Andrei, F., Siegling, A. B., Aloe, A. M., Baldaro, B., \& Petrides, K. V. (2016). The incremental validity of the trait emotional intelligence questionnaire (TEIQue): A systematic review and meta-analysis. Journal of Personality Assessment, 98, 261-276.

Ashton, M. C., \& Lee, K. (2001). A theoretical basis for the major dimensions of personality. European Journal of Personality, 15(5), 327-353.

Ashton, M. C., \& Lee, K. (2005). Honesty-humility, the big five, and the five-factor model. Journal of Personality, 73(5), 1321-1354.

Ashton, M. C., Lee, K., \& Son, C. (2000). Honesty as the sixth factor of personality: Correlations with Machiavellianism, primary psychopathy, and social adroitness. European Journal of Personality, 14(4), 359-368.

Bastian, V. A., Burns, N. R., \& Nettelbeck, T. (2005). Emotional intelligence predicts life skills, but not as well as personality and cognitive abilities. Personality and Individual Differences, 39(6), 1135-1145.

Briley, D. A., \& Tucker-Drob, E. M. (2014). Genetic and environmental continuity in personality development: A meta-analysis. Psychological Bulletin, 140(5), 1303-1331.

Carmeli, A. (2003). The relationship between emotional intelligence and work attitudes, behavior and outcomes: An examination among senior managers. Journal of Managerial Psychology, 18(8), 788-813.

Ceschi, A., Sartori, R., Dickert, S., \& Costantini, A. (2016). Grit or honesty-humility? New insights into the moderating role of personality between the health impairment process and counterproductive work behavior. Frontiers in Psychology, 7, 1799.

Chirumbolo, A., Picconi, L., Morelli, M., \& Petrides, K. V. (2019). The assessment of trait emotional intelligence: Psychometric characteristics of the TEIQue-full form in a large Italian adult sample. Frontiers in Psychology, 9, 2786. https://doi.org/10.3389/fpsyg. 2018.02786

Clark, L., \& Watson, D. (1995). Constructing validity: Basic issues in objective scale development. Psychological Assessment, 7, 309 319.

Cooper, A., \& Petrides, K. V. (2010). A psychometric analysis of the trait emotional intelligence questionnaire-short form (TEIQue-SF) using item response theory. Journal of Personality Assessment, 92(5), 449-457.

Cote, S., \& Miners, C. T. (2006). Emotional intelligence, cognitive intelligence, and job performance. Administrative Science Quarterly, $51(1), 1-28$.

Dåderman, A. M., \& Ragnestål-Impola, C. (2019). Workplace bullies, not their victims, score high on the dark triad and extraversion, and low on agreeableness and honesty-humility. Heliyon, 5(10), e02609. https://doi.org/10.1016/j.heliyon.2019.e02609.

Dåderman, A. M., Ingelgård, A., \& Koopmans, L. (2020). Cross-cultural adaptation, from Dutch to Swedish language, of the individual work 
performance questionnaire. WORK: A Journal of Prevention, Assessment, and Rehabilitation, 65(1), 97-109.

DeShong, H. L., Grant, D. M., \& Mullins-Sweatt, S. N. (2015). Comparing models of counterproductive workplace behaviors: The five-factor model and the dark triad. Personality and Individual Differences, 74, 55-60.

Donnellan, M. B., Oswald, F. L., Baird, B. M., \& Lucas, R. E. (2006). The mini-IPIP scales: Tiny-yet-effective measures of the big five factors of personality. Psychological Assessment, 18(2), 192-302.

Feher, A., Gonggu, Y., Saklofske, D. H., Plouffe, R. A., \& Gau, Y. (2019). An investigation of the psychometric properties of the Chinese trait emotional intelligence questionnaire short form (Chinese TEIQueSF). Frontiers in Psychology, 10, 435. https://doi.org/10.3389/ fpsyg.2019.00435s.

Fernandéz del Río, E., Ramos-Villagrasa, P. J., and Barrada, J. R. (2020). Bad guys perform better? The incremental predictive validity of the Dark Tetriad over Big Five and Honesty-Humility. Personality and Individual Differences, 154. https://doi.org/10.1016/j.paid.2019. 109700

Furnham, A., Richards, S. C., \& Paulhus, D. L. (2013). The dark triad of personality: A 10 year review. Social and Personality Psychology Compass, 7(3), 199-216.

Greco, L. M., O’Boyle, E. H., Cockburn, B. S., and Yuan, Z. (2018). Meta-analysis of coefficient alpha: A reliability generalization study. Journal of Management Studies, 55(4), doi: 10:1111/joms.12328.

Heilbrun, K. (1992). The role of psychological testing in forensic assessment. Law and Human Behavior, 16, 257-272.

Hilbig, B. E., Zettler, I., Leist, F., \& Heydasch, T. (2013). It takes two: Honesty-humility and agreeableness differentially predict active versus reactive cooperation. Personality and Individual Differences, 54(5), 598-603.

Hodson, G., Hogg, S. M., \& MacInnis, C. C. (2009). The role of "dark personalities" (narcissism, Machiavellianism, psychopathy), big five personality factors, and ideology in explaining prejudice. Journal of Research in Personality, 43(4), 686-690.

Jacobs, I., Sim, C.-W., Zimmermann, J., et al. (2015). The German TEIQue-SF: Factorial structure and relations to agentic and communal traits and mental health. Personality and Individual Differences, 72, 189-194.

Johnson, M. K., Rowatt, W. C., \& Petrini, L. (2011). A new trait on the market: Honesty-humility as a unique predictor of job performance ratings. Personality and Individual Differences, 50(6), 857-862.

Jonason, P. K., Slomski, S., \& Partyka, J. (2012a). The dark triad at work: How toxic employees get their way. Personality and Individual Differences, 52(4), 449-453.

Jonason, P. K., Webster, G. D., Schmitt, D. P., Li, N. P., \& Crysel, L. (2012b). The antihero in popular culture: Life history theory and the dark triad personality traits. Review of General Psychology, 16(2), 192-199.

Jones, D. N., \& Paulhus, D. L. (2014). Introducing the short dark triad (SD3): A brief measure of dark personality traits. Assessment, 21(1), 28-41.

Joseph, D. L., \& Newman, D. A. (2010). Emotional intelligence: An integrative meta-analysis and cascading model. Journal of Applied Psychology, 95, 54-78.

Joseph, D. L., Jin, J., Newman, D. A., \& O’Boyle, E. H. (2015). Why does self-reported emotional intelligence predict job performance? A meta-analytic investigation of mixed EI. Journal of Applied Psychology, 100(2), 298-342.

Koopmans, L., Bernaards, C., Hildebrandt, V., van Buuren, S., van der Beek, A. J., \& de Vet, H. C. (2012). Development of an individual work performance questionnaire. International Journal of Productivity and Performance Management, 62(1), 6-28.

Laborde, S., Allen, M. S., \& Guillén, F. (2016). Construct and concurrent validity of the short- and long-form versions of the trait emotional intelligence questionnaire. Personality and Individual Differences, $101,232-235$.

LeBreton, J. M., Shiverdecker, L. K., \& Grimaldi, E. M. (2018). The dark triad and workplace behavior. Annual Review of Organizational Psychology and Organizational Behavior, 5, 387-414.

Lee, K., Ashton, M. C., \& de Vries, R. E. (2005). Predicting workplace delinquency and integrity with the HEXACO and five-factor models of personality structure. Human Performance, 18(2), 179-197.

Lopes, P. N., Grewal, D., Kadis, J., Gall, M., \& Salovey, P. (2006). Evidence that emotional intelligence is related to job performance and affect and attitudes at work. Psicothema, 18, 132-138.

Malouff, J. M., Schutte, N. S., \& Thorsteinsson, E. B. (2014). Trait emotional intelligence and romantic relationship satisfaction: A metaanalysis. The American Journal of Family Therapy, 42(1), 53-66.

McCrae, R. R., \& Costa Jr., P. T. (1997). Personality trait structure as a human universal. American Psychologist, 52(5), 509-516.

Miao, C., Humphrey, R. H., \& Qian, S. (2016). A meta-analysis of emotional intelligence and work attitudes. Journal of Occupational and Organizational Psychology., 90, 177-202. https://doi.org/10.1111/ joop.12167.

Miao, C., Humphrey, R. H., \& Qian, S. (2017). Are the emotionally intelligent good citizens or counterproductive? A meta-analysis of emotional intelligence and its relationships with organizational citizenship behavior and counterproductive work behavior. Personality and Individual Differences, 116, 144-156.

Nagler, U. K., Reiter, K. J., Furtner, M. R., \& Rauthmann, J. F. (2014). Is there a "dark intelligence"? Emotional intelligence is used by dark personalities to emotionally manipulate others. Personality and Individual Differences, 65, 47-52.

Nelis, D., Quoidbach, J., Mikolajczak, M., \& Hansenne, M. (2009). Increasing emotional intelligence: (how) is it possible? Personality and Individual Differences, 47(1), 36-41.

Neustadt, E. A., Chamorro-Premuzic, T., \& Furnham, A. (2011). Attachment at work and performance. Attachment \& Human Development, 13(5), 471-488.

O’Boyle, E. H., Forsyth, D. R., Banks, G. C., \& McDaniel, M. A. (2012). A meta-analysis of the dark triad and work behavior: A social exchange perspective. Journal of Applied Psychology, 97(3), 557-579.

O'Connor, P., Nguyen, J., \& Anglim, J. (2017). Effectively coping with task stress: A study of the validity of the trait emotional intelligence questionnaire-short form (TEIQue-SF). Journal of Personality Assessment, 99(3), 304-314.

O'Connor, P. J., Hill, A., Kaya, M., \& Martin, B. (2019). The measurement of emotional intelligence: A critical review of the literature and recommendations for researchers and practitioners. Frontiers in Psychology, 10, 1116. https://doi.org/10.3389/fpsyg.2019.01116.

Patrick, C. J. (Ed.). (2018). Handbook of psychopathy (2nd ed.). New York, NY: Guilford Press.

Paulhus, D. L., \& Williams, K. M. (2002). The dark triad of personality: Narcissism, Machiavellianism, and psychopathy. Journal of Research in Personality, 36(6), 556-563.

Paulhus, D. L., Robins, R. W., Trzesniewski, K. H., \& Tracy, J. L. (2004). Two replicable suppressor situations in personality research. Multivariate Behavioral Research, 39(2), 303-328.

Perera, H. N. (2015). The internal structure of responses to the trait emotional intelligence questionnaire-short form: An exploratory structural equation Modelling approach. Journal of Personality Assessment, 97(4), 411-423.

Petrides, K. V. (2001). A psychometric investigation into the construct of emotional intelligence. Doctoral Dissertation: University College London.

Petrides, K. V. (2009). Psychometric properties of the trait emotional intelligence questionnaire. In C. Stough, D. H. Saklofske, \& J. D. Parker (Eds.), Advances in the assessment of emotional intelligence (pp. 85-101). New York: Springer. 
Petrides, K. V. (2011). Ability and trait emotional intelligence. In: T. Chamorro-Premuzic, A. Furnham, and von Stumm (Eds.), The Wiley-Blackwell handbook of individual differences (pp. 656678). New York: Wiley.

Petrides, K. V., \& Furnham, A. (2000). On the dimensional structure of emotional intelligence. Personality and Individual Differences, 29(2), 313-320.

Petrides, K. V., \& Furnham, A. (2001). Trait emotional intelligence: Psychometric investigation with reference to established trait taxonomies. European Journal of Personality, 15(6), 425-448.

Petrides, K. V., \& Furnham, A. (2006). The role of trait emotional intelligence in a gender-specific model of organizational variables. Journal of Applied Social Psychology, 36(2), 552-569.

Petrides, K. V., Vernon, P. A., Schermer, J. A., Ligthart, L., Boomsma, D. I., \& Veselka, L. (2010). Relationships between trait emotional intelligence and the big five in the Netherlands. Personality and Individual Differences, 48(8), 906-910.

Petrides, K. V., Vernon, P. A., Schermer, J. A., \& Veselka, L. (2011). Trait emotional intelligence and the dark triad traits of personality. Twin Research and Human Genetics, 14(1), 35-41.

Petrides, K. V., Mikolajczak, M., Mavrovelli, S., Sánches-Ruiz, M.-J., Furnham, A., \& Pérez-González, J.-C. (2016). Recent developments in trait emotional intelligence research. Emotional Review, 8, 335341

Plouffe, R. A., Saklofske, D. H., \& Smith, M. M. (2017). The assessment of sadistic personality: Preliminary psychometric evidence for a new measure. Personality and Individual Differences, 104, 166-171.

Ramos-Villagrasa, P. J., Barrada, J. R., Fernández-del-Río, E., \& Koopmans, L. (2019). Assessing job performance using brief selfreport scales: The case of the individual work performance questionnaire. Journal of Work and Organizational Psychology, 35, 195205

Salgado, J. F. (1997). The five factor model of personality and job performance in the European community. Journal of Applied Psychology, 82(1), 30-43.

Saucier, G. (2009). Recurrent personality dimensions in inclusive lexical studies: Indications for a big six structure. Journal of Personality, 77(5), 1577-1614.

Schönbrodt, F. D., \& Perugini, M. (2013). At what sample size do correlations stabilize? Journal of Research in Personality, 47, 609-612.

Schutte, N. S., Malouff, J. M., Bobik, C., Coston, T. D., Greeson, C., Jedlicka, C., ..., and Wendorf, G. (2001). Emotional intelligence and interpersonal relations. The Journal of Social Psychology, 141(4), $523-536$

Sibley, C. G. (2012). The mini-IPIP6: Item response theory analysis of a short measure of the big-six factors of personality in New Zealand. New Zealand Journal of Psychology, 41(3), 21-31.

Sibley, C. G., \& Pirie, D. J. (2013). Personality in New Zealand: Scale norms and demographic differences in the mini-IPIP6. New Zealand Journal of Psychology, 42(1), 13-30.
Sibley, C. G., Luyten, N., Purnomo, M., Mobberley, A., Wootton, L. W., Hammond, M. D., et al. (2011). The mini-IPIP6: Validation and extension of a short measure of the big-six factors of personality in New Zealand. New Zealand Journal of Psychology, 40(3), 142-159.

Siegling, A. B., Vesely, A. K., Petrides, K. V., \& Saklofske, D. H. (2015). Incremental validity of the trait emotional questionnaire-short form (TEIQue-SF). Journal of Personality Assessment, 97(5), 525-535.

Stamatopoulou, M., Galanis, P., \& Prezerakos, P. (2016). Psychometric properties of the Greek translation of the trait emotional intelligence questionnaire-short form (TEIQue-SF). Personality and Individual Differences, 95, 80-84.

Swedish Research Council (2002). Forskningsetiska principer inom humanistisk-samhällsvetenskaplig forskning [Ethical research principles in humanities-social science research]. Downloaded 4/2/ 2018from http://www.codex.vr.se/texts/HSFR.pdf

Szczygiel, D., \& Mikolajczak, M. (2018). Is it enough to be an extrovert to be liked? Emotional competence moderates the relationship between extraversion and peer-rated likeability. Frontiers in Psychology, 9, 804.

Szczygiel, D., Jasielska, A., \& Wytykowska, A. (2015). Psychomteric properties of the polish version of the trait emotional intelligence questionnaire-short form. Polish Psychological Bulletin, 46(3), $447-459$.

Van Rooy, D., \& Visewesvaran. (2004). Emotional intelligence: A metaanalitic investigation of predictive validity and nomological net. Journal of Vocational Behavior, 65, 71-95.

Vernon, P. A., Villani, V. C., Schermer, J. A., \& Petrides, K. V. (2008a). Phenotypic and genetic associations between the big five and trait emotional intelligence. Twin Research and Human Genetics, 11(5), 524-530.

Vernon, P. A., Villani, V. C., Vickers, L. C., \& Harris, J. A. (2008b). A behavioral genetic investigation of the dark triad and the big 5 . Personality and Individual Differences, 44(2), 445-452.

Veselka, L., Schermer, J. A., Petrides, K. V., Cherkas, L. F., Spector, T. D., \& Vernon, P. A. (2009). A general factor of personality: Evidence from the HEXACO model and a measure of trait emotional intelligence. Twin Research and Human Genetics, 12(5), 420-424.

Zampetakis, L. A. (2011). The measurement of trait emotional intelligence with TEIQue-SF: An analysis based on unfolding item response theory models. In N. M. Ashkanasy, W. J. Zerbe, \& C. E. J. Härtel (Eds.), What have we learned? Ten years on research on emotion in organizations 7 (pp. 289-315). Emerald Group Publishing.

Zeidner, M., Matthews, G., \& Roberts, R. D. (2004). Emotional intelligence, health, and well-being nexus: What we have learned and what we have missed? Applied Psychology, Health and WellBeing, 4, 1-30.

Publisher's Note Springer Nature remains neutral with regard to jurisdictional claims in published maps and institutional affiliations. 